\title{
FACILITATING CRITICAL THINKING THROUGH ONLINE COURSES
}

Margaret Lunney, $R N, P h D$

The College of Staten Island

Keville Frederickson, $R N, P h D$

Lehman College

Arlene Spark, EdD, RD, FADA, FACN

Hunter College

Georgia McDuffie, RN, PhD

Medgar Evers College, CUNY

\begin{abstract}
Development of critical thinking abilities is essential for students in clinical disciplines of the health sciences. Past research has shown that critical thinking is a learned skill that can be fostered through teaching strategies. Ten educational strategies that were developed and tested by the authors in online courses are presented to assist instructors to encourage students in the health sciences to improve critical thinking processes.
\end{abstract}

\section{KEYWORDS}

Critical Thinking, Health Science, Strategies

\section{INTRODUCTION}

Advanced abilities in critical thinking processes for clinical practice should be a goal of all nursing and health science programs. With the complexity of healthcare today, critical thinking ability is crucial for problem solving and the processing of relevant information. Graduates of health science programs must use critical thinking to decide how to help individuals, families, and communities to promote, protect and restore health. Because the phenomenon of human health is so complex, critical thinking abilities are needed to understand and apply health knowledge. The purpose of this paper is to provide ten strategies to facilitate students' critical thinking for faculty in nursing, nutrition, and the other health sciences who wish to develop their own online courses. These strategies, based on existing literature sources, have been used and tested by the authors. Examples are provided with each strategy of student results.

\section{CRITICAL THINKING}

Critical thinking is a subset of the three thinking processes of reasoning, making judgments and decisions, and problem solving $[1, \mathrm{p} .8]$. In using these three types of thinking throughout life and clinical practice, the process of thinking critically occurs some of the time, e.g., when a person weighs the evidence to make a decision. The three key features of critical thinking are that it involves "effectiveness, novelty, 
and self direction" [1, p.11]. Critical thinking is not a skill that transfers to other unrelated thinking processes, but is a process that occurs in relation to specific domain content. Content knowledge is needed in order to achieve appropriate critical thinking in knowledge domains. An important advantage of using critical thinking processes is that it helps learners to overcome their negative egocentrism and sociocentrism $[2,3]$.

Through collaborative use of critical thinking processes with other students during reasoning, making decisions, and problem solving, learners gain a foundation for independent and interdependent critical thinking. Ability to use critical thinking varies, depending on comprehension, self-assuredness, level of maturity, experience with critical thinking processes, and other variables [2].

Through critical thinking, students focus on the processes of learning rather than just attaining facts about phenomena [4]. Critical thinking helps learners to create and apply new knowledge to real-world situations. When learners think critically, they become actively responsible for their own education, which can lead to wisdom--not just the learning of new information $[5, \mathrm{p} .15)$.

Critical thinking contributes to the rational and reflective processes of making judgments in clinical practice [2]. Clarity in judgment involves a breadth of knowledge and a depth of understanding which, when nurtured by educators, lay the foundation for practical application and the gaining of wisdom. Critical thinking includes the ability to tolerate and manage ambiguity as part of the complexity of human experiences and professional roles. To tolerate and manage ambiguity means that health professionals embrace, or at least accept, the ambiguity of clinical judgments in health care instead of having emotional or avoidance reactions to the ambiguity.

More than two centuries ago, Socrates devised a method of questioning and analysis that required clarity of thinking and logical consistency [3]. The Socratic method of questioning set the stage for the study of critical thinking. More recently, critical thinking has been extensively studied, showing that people with the same degree of education and professional preparation can and do vary widely in basic thinking abilities $[1$, p. $8 ; 6$, p. $60 ; 7$, p. 8$]$. The research also shows that thinking abilities can be improved through focused educational activities and individual efforts $[2,7,8,9,10]$. Based on previous research on basic thinking abilities, faculty members who teach nursing and health science courses should assume that the students in their classes vary in thinking abilities and that their thinking abilities can be improved and transferred to clinical practice. The facilitation of critical thinking is best achieved in conjunction with domain content, so incorporating these processes within online courses on any health science topic will help students to further develop the use of critical thinking for clinical practice $[1$, p. $8 ; 2]$.

There are many different theoretical perspectives on critical thinking that mainly derive from the disciplines of psychology, educational psychology, and cognitive psychology, e.g., the views of cognitive scientists as summarized by Willingham [1, p. 8]. Using one of these views is important because students need to know specific critical thinking metacognitive concepts to focus on using them. An example is when students are prompted to analyze a clinical situation by considering both sides of the issue before making a decision. To identify the critical thinking concepts that are relevant to nursing, Scheffer and Rubenfeld [11, p. 352] conducted a Delphi study of 56 nurse experts in critical thinking. The results were a definition and description of critical thinking in nursing as an essential component of professional accountability and quality nursing care. "Critical thinkers in nursing exhibit these habits of mind: confidence, contextual perspective, creativity, flexibility, inquisitiveness, intellectual integrity, intuition, open-mindedness, perseverance, and reflection. Critical thinkers in nursing practice the cognitive skills of analyzing, applying standards, discriminating, information seeking, logical reasoning, predicting and 
transforming knowledge" [11, p. 357; 4] (see Table 1). The research-based strategies for online courses proposed here are designed to facilitate these seven cognitive skills and 10 habits of mind in online courses in nursing, nutrition, and other health sciences.

\begin{tabular}{|c|c|}
\hline Characteristics & Definitions \\
\hline \multicolumn{2}{|l|}{ Cognitive Skills } \\
\hline Analyzing & $\begin{array}{l}\text { Separating or breaking a whole into parts to discover the nature, } \\
\text { function and relationships }\end{array}$ \\
\hline Applying Standards & $\begin{array}{l}\text { Judging according to established personal, professional, or social rules } \\
\text { or criteria }\end{array}$ \\
\hline Discriminating & $\begin{array}{l}\text { Recognizing differences and similarities among things or situations and } \\
\text { distinguishing carefully as to category or rank }\end{array}$ \\
\hline Information Seeking & $\begin{array}{l}\text { Searching for evidence, facts or knowledge by identifying relevant } \\
\text { sources and gathering objective, subjective, historical and current data } \\
\text { from those sources. }\end{array}$ \\
\hline Logical Reasoning & $\begin{array}{l}\text { Drawing inferences or conclusions that are supported in or justified by } \\
\text { evidence }\end{array}$ \\
\hline Predicting & Envisioning a plan and its consequences \\
\hline $\begin{array}{l}\text { Transforming } \\
\text { Knowledge }\end{array}$ & $\begin{array}{l}\text { Changing or converting the condition nature, form or function of } \\
\text { concepts among contexts }\end{array}$ \\
\hline \multicolumn{2}{|l|}{ Habits of the Mind } \\
\hline Confidence & Assurance of one's reasoning abilities \\
\hline Contextual perspective & $\begin{array}{l}\text { Consideration of the whole situation, including relationships, } \\
\text { background, and environment, relevant to some happening }\end{array}$ \\
\hline Creativity & $\begin{array}{l}\text { Intellectual inventiveness used to generate, discover, or restructure } \\
\text { ideas; imagining alternatives }\end{array}$ \\
\hline Flexibility & $\begin{array}{l}\text { Capacity to adapt, accommodate, modify or change thoughts, ideas and } \\
\text { behaviors }\end{array}$ \\
\hline Inquisitiveness & $\begin{array}{l}\text { An eagerness to know by seeking knowledge and understanding } \\
\text { through observation and thoughtful questioning in order to explore } \\
\text { possibilities and alternatives }\end{array}$ \\
\hline Intellectual integrity & $\begin{array}{l}\text { Seeking the truth through sincere. honest processes, even if the results } \\
\text { are contrary to one's assumptions and beliefs }\end{array}$ \\
\hline Intuition & Insightful sense of knowing without conscious use of reason \\
\hline Open-mindedness & $\begin{array}{l}\text { A viewpoint characterized by being receptive to divergent views and } \\
\text { sensitive to one's biases }\end{array}$ \\
\hline Perseverance & Pursuit of a course with determination to overcome obstacles \\
\hline Reflection & $\begin{array}{l}\text { Contemplation upon a subject, especially one's assumptions and } \\
\text { thinking for purposes of deeper understanding and self-evaluation }\end{array}$ \\
\hline
\end{tabular}

Table 1. Critical Thinking Categories and Definitions [11]

\section{STRATEGIES TO FACILITATE CRITICAL THINKING THROUGH ONLINE COURSES}

Thinking processes can be improved through teaching, coaching and practice, so specific educational strategies can be used in online courses to facilitate students' critical thinking processes. The following 
ten strategies are proposed: (1) ask-questions that can be answered through information seeking, (2) expect students to describe the meanings of their required readings in their own words, (3) motivate students to use effort through grading criteria, (4) stimulate students to give examples of concepts or theories being studied, (5) provide case studies or other examples for application of class content, (6) prompt students to ask questions of each other and the instructor; (7) phrase questions so that additional independent research or reading is required, (8) promote student debates on controversial subjects within the discipline, (9) require students to use journaling, and (10) reinforce students' use of critical thinking (see Table 2).

\begin{tabular}{|ll|}
\hline 1. & Ask questions of students \\
\hline 2. & Expect students to formulate answers to questions in their own words \\
\hline 3. & Motivate students to use effort through grading criteria for participation in discussions \\
\hline 4. & Stimulate students to give examples of concepts being studied \\
\hline 5. & Provide case studies or other examples for student application of concepts and theories \\
\hline 6. & Prompt students to ask questions of themselves, each other and the instructor \\
\hline 7. & Phrase questions to students that require additional independent research or reading \\
\hline 8. & Promote student debates on controversial subjects within the discipline \\
\hline 9. & Require a course-related journal \\
\hline 10. & Reinforce students' use of critical thinking through positive reinforcement \\
\hline
\end{tabular}

Table 2. Summary: Teaching Strategies to Facilitate Critical Thinking in Online Courses

\section{A. Asking Questions}

A basic strategy that has strong research support is to ask students questions and expect them to find and provide the answers $[1,8,10]$. Questions can be factual, descriptive, clarifying, or value-seeking. Students are motivated to explore the unknown and make cognitive connections to the known by seeking clarification. Questions can help students move through a process of deductive and inductive reasoning. Questions hold students accountable and help them to internalize habits of critical thinking while conditioning them to use patterns of critical thinking behaviors through guided practice.

The answers to questions do not have to be difficult or hard to find; the answers can be found, for example, in the assigned readings for a course. But, the effort of looking for the answers generates the cognitive skill of information seeking. Questions at a higher level of ability are those that require the cognitive skills of analysis and logical reasoning and questions that generate further questions and inquiry. These types of questions generate the cognitive skill of transformation of knowledge and development of the habits of mind of flexibility and creativity.

Example of Student Outcomes. In a course on community health nursing, the question was: What are Advance Directives? One student provided an answer and other students provided further clarification, such as below:

To add to Emily's comments, the Patient Self-Determination Act requires healthcare providers to discuss advance directives with patients and include in the health care record whether the patient has signed advance directives. I believe that it is crucial for all people to have advance directives. I often encounter situations where patients do not have advance directives. If their status rapidly changes and they are no longer able to make decisions, families often disagree about what treatment should be given and what treatment should be withheld. To avoid any confusion, families should discuss their wishes with each 
other and complete advance directives. This ensures that their wishes are respected and carried out.

\section{B. Writing in Own Words}

A second strategy is to expect students to formulate the answers to questions in their own words. This encourages development of the habit of mind, flexibility, and may also require the cognitive skills of analyzing and logical reasoning, albeit sometimes at a basic level. Students who cannot formulate the answers in their own words can use the words of the authors they are reading, but they should put them in quotation marks and cite the page numbers. In our experience, students generally do not quote from the book, even though they have the opportunity to do so. It may be that they want to appear smart enough to peers to be able to write it in their own words. Writing in one's own words is also encouraged by developing assignments that require students to provide their opinions based on course content.

\section{Example of Student Outcomes}

In a food politics course, the teacher asked students their opinions of the Breastfeeding Promotion Act (United States House of Representatives, 2007), which amends the Civil Rights Act of 1964 to include lactation (breastfeeding, including expression of milk) as protected conduct. One student posted the following opinion:

As we review the legislation and policy efforts to encourage and protect breastfeeding as a public health issue, I started to consider what is behind the letter of the law. I thought Margaret brought up a good distinction in the Pennsylvania law where Republicans debated over the wording right to breastfeed...replaced by freedom to breastfeed. States' laws in the US literally provide the "freedom" to breastfeed and not the right of a child to receive breastmilk. Consider the Texas and California statutes, which prohibit the sale of breastmilk. As breastmilk is the ideal food for (almost all) newborns and infants through at least 6 months of age, then child should have a "right" to breastmilk. But, that's not the case, to wit: suppose an adopted infant must be cared for at a time when he should be receiving breastmilk. How is this infant protected under current states' policies for breastfeeding? The answer - the baby is not protected at all. The focus of state legislation and workplace policy is to ensure the freedom of the lactating mother to feed her baby from the breast. This strikes me as misdirected policy. The primary health benefits of breastfeeding are acquired by the infant, not the mother. Policy changes that protect and encourage breastfeeding should start by protecting the infant's right to breastmilk.

\section{Plagiarism}

A related issue is that students may post a response as if it is their own writing but it was plagiarized [12]. Plagiarism of Internet sources is particularly prevalent in online courses. Cyber-plagiarism can be prevented, or at least thwarted, by using a combination of strategies (see Table 3). The first step is to be aware of plagiarism. All teachers need to educate themselves and their students about plagiarism.

\begin{tabular}{|ll|}
\hline 1. & Develop assignments that are clear to the students. \\
\hline 2. & $\begin{array}{l}\text { Provide a list of appropriate subjects. Assign narrowly focused topics rather than broad } \\
\text { general ones, or ask students to write about current events as they relate to class } \\
\text { materials. }\end{array}$ \\
\hline 3. & $\begin{array}{l}\text { Require specific components in assignments, such as headings, number of pages, } \\
\text { referencing style. }\end{array}$ \\
\hline $4 . \quad$ Require process steps for the assignment, i.e., stagger due dates for different parts of a \\
\hline
\end{tabular}




\begin{tabular}{|ll|}
\hline & $\begin{array}{l}\text { paper. For example, the bibliography can be due a week before the final paper, or } \\
\text { specify what materials students can use, or assign two or three smaller papers } \\
\text { throughout the term rather than a single large one. }\end{array}$ \\
\hline 5. & $\begin{array}{l}\text { Have students include an annotated bibliography as part of the assignment, or ask them } \\
\text { to include a photocopy of the first page of each article they cite. }\end{array}$ \\
\hline $6 . \quad$ & Require most references to be up-to-date: no more than 3 to 5 years old. \\
\hline 7. & $\begin{array}{l}\text { Require an essay about the learning process, e.g., on the day the paper is due, ask } \\
\text { students to write an essay summarizing the salient points. In a traditional face-to- face } \\
\text { course, this would be accomplished by an oral summary of the work. }\end{array}$ \\
\hline 8. & $\begin{array}{l}\text { Require students to submit notes or outlines with their paper because you are looking for } \\
\text { evidence of original thought. }\end{array}$ \\
\hline 9. & Change the paper topics each time the course is offered. \\
\hline $10 . \quad$ Require that students provide complete URLs for online articles. \\
\hline
\end{tabular}

Course materials should be developed that discuss the benefits of citing sources, and make the penalties clear for intentionally trying to pass off someone else's work as one's own. Teachers also need to adopt strategies that make their assignments sufficiently unique so that students in the course will do their own work to fulfill the task requirements. Assignments can be designed so that only newly written papers will meet the grading criteria.

\section{Grading}

Because studies have shown that individual effort improves thinking abilities $[1, \mathrm{p} .8 ; 7,10]$, a third strategy is to motivate students to apply effort. Grading is a traditional and time-honored approach to motivate students' to try harder.

Each of the authors of this paper use a different grading rubric for students' postings in course Discussion Boards. Lunney uses a weekly grading system in which 95 is awarded for excellent effort, with at least 12 postings that include 6 responses to other students' postings. Grades at 5 point increments are awarded down to 70, which is given for minimal effort that week. Each grade is associated with specific criteria and students must first use the criteria for self evaluation before they receive the instructor's grade. Frederickson pro-rates the credits so that students may receive between 5 and 10 points each unit depending on the complexity of the material and the quality of the student's answers. The teacher posts examples of a 5 point answer and a 10 point answer to motivate students to try for a higher number of points. Sparks uses a 5-point grading system, from 0 to 4 , with 4 being awarded for excellent responses and 0 being awarded for unacceptable responses. To achieve a grade of 4 , the posting needs to be accurate, original, relevant, teaches something new, and is well written. McDuffie uses a grading system that gives students points when online assignments are completed in totality within the specified time period. Students may earn a maximum of 5 points depending upon the accuracy with which assignments are completed.

\section{Examples of Students Outcomes}

In online courses using Lunney's grading system, a majority of students post 10 to 12 times and respond to other students' answers on that week's topic in 6 of the 12 postings. The goal of most students is to receive a 95 for each week's discussion, which helps to ensure a good course grade. In a course taught by Frederickson on evidence based practice, a student presented each of the categories of evidence with one example; a minimal response for which 5 points were awarded. Another student identified each of the 
categories of evidence and discussed how a descriptive study could be modified to achieve a higher ranking; this student was awarded 10 points. The points for each unit are averaged for the course participation grade. With Sparks method, each student's contribution to the discussion is evaluated 10 times during the semester ( 1 absence is permitted without penalty). The range of possible points per session is 0 to 4 , thus 40 is the maximum possible score for the discussion segment of the course. McDuffie uses points that are translated into a percentage of the total grade. Students are expected to post weekly achieving a maximum of 5 points per week, which, at the end of the semester, equals $20 \%$ of the total grade. Failure to post impacts the total grade. One student wrote as part of her evaluation of the course:

I like online classes better than on-campus classes because it gives me the time I need to research and formulate my thoughts before posting them, and I'm not intimidated by the fast thinkers and the more verbal students. While I thoroughly enjoyed reading the postings because I learned so much, I felt I had something to contribute both from my experience and the required readings. The first meeting helped to put me on track, but I dreaded the last session until one of the other students said to me, 'I always looked forward to reading your postings. They were so insightful.' I love on-line courses.

\section{Examples of Concepts}

A fourth strategy is to ask students for examples of concepts. The strategy of asking for examples stimulates the cognitive skills of analyzing and discriminating and the habits of mind of flexibility and reflection. The need to provide examples gives students opportunities to connect what they are learning to their past knowledge and their personal experiences.

\section{Examples of Students' Outcomes}

The following posting took place in a discussion of ethics:

Last month I was asked to co-sign a consent for surgery, but I thought that the patient was not clear about what he was signing. The patient was not literate enough to read the consent form and the physician did not verbally explain everything that was on the consent form. In this case, the principle of autonomy was being violated. To resolve the issue, I asked the physician, with the patient listening, to explain the content of the consent form and then validated that the patient understood the explanation and agreed to the surgery. After this was completed, I co-signed the form. Afterwards, the physician and I briefly discussed the related ethical issues.

The following postings are students' responses to an assignment in which students were asked to propose new nutrition objectives to be included in Healthy People 2020:

- Increase the number of urban farms and other urban food production alternatives.

- Increase food security among US households in a manner that provides optimal and equitable nutrition and health as well as to reduce hunger.

- Increase the availability of reasonably priced low-fat, low-sodium, nutrient-dense foods in commercial food outlets.

- Eliminate the availability in schools of foods that would compete with healthy foods.

\section{E. Application}

Strategy five is to motivate students to apply the content to a case study, a published article, or a specific task that requires decision making or problem solving. This can be done by including application of content in the grading criteria, and giving students higher grades for successful application. This is 
important because evidence shows that students do not necessarily transfer critical thinking abilities to clinical practice [2]. Students also need opportunities to practice the specific types of critical thinking processes that are needed for specific kinds of content [1, p.8]. In a course about the research process, for example, a research article can be supplied each week for students to apply the content learned in required chapters.

\section{Examples of Students Outcomes}

The following is from an undergraduate student's posting in a research course, with the weekly topic being quantitative research designs:

This study is nonexperimental quantitative research - no manipulation is introduced for obvious ethical reasons. There is also no control group. It is a descriptive, correlational study. I think it is a within-subjects design as far as type of group comparison because we are looking at different levels of distress in relation to different responses from a parent within the same parent/child dyad. Since it collects data multiple times in a short period, I think, it is a cross-sectional study. With respect to observance of variables, it is a prospective study and it occurs in real-world setting, a urology clinic. The inclusion was based on 4 criteria which was a way to control intrinsic subject characteristics. Since the sample size was very small, I think the statistical conclusion validity, as well as internal and external validity were undermined, although no threats to internal validity or problems with external validity were identified. It is hard, at least for me, to determine to what extent is this study externally valid, which is a main question for evidence-based practice purposes. As mentioned before, sample size is the major limitation in this study. The author acknowledges this fact and maintains caution in interpretation of the research findings.

\section{F. Prompt Students to Ask Questions}

Asking questions about any topic, strategy six, facilitates the effectiveness, novelty, and self direction of critical thinking by generating additional information for improved reasoning, judgments and decision making, and problem solving [1, p.8]. Helping students to ask the "right questions" to guide critical thinking can be accomplished by prompting them to ask questions of themselves, each other, and the instructor related to the content. This strategy works especially well when used along with application of the content to a decision making or problem solving task (see above strategy). Twelve major questions to best guide critical thinking are summarized and explained by Browne and Keeley [8], ranging from what words or phrases are ambiguous (chapter 2) to what reasonable conclusions are possible (chapter 13). Paul and Elder [10] provide many possible questions that students can ask themselves or others.

\section{Examples of Students' Outcomes}

In an online course on family theory in nursing, the topic was family structure. Students were asked to identify the composition of modern families. The class included a number of students from different countries. A student from Africa identified families divided by war and migration. The faculty asked the students to discuss how this division affected family roles and to think of other family structure changes that would result in changes in family roles. The outcome was that students explored different situations within and outside the family that might change family roles and asked each other questions such as: If a relative moves in, how would that affect roles? How close a relationship would it have to be to invite or not invite a relative to live with your family?

In a discussion about Public Law 108-265, which mandates local wellness policies in schools, an example 
of a student's use of questions was as follows:

My first question is: Why use words like 'meet minimum requirements'? Why not set the bar higher? As Michele Simon discusses in Appetite for Profit, schools have the rare opportunity to teach kids what it means to be healthy--to eat a well-balanced diet and to by physically active on a daily basis. Why water down a potentially influential mandate by making the requirements vague, using words like (bare) 'minimum' and 'least possible'? My next question is: are they really requirements? Where does it discuss what the ramifications are if a school doesn't follow through? Is the ONE person (as minimally required by the mandate) that is responsible for ensuring that the school meets the requirements going to be penalized? Why not require a team of people, expert in their field to be responsible, as the model school policy suggests?

\section{G. Questions Requiring Additional Research}

Strategy seven is for instructors to phrase questions so that additional independent research or reading is required. A case study can be presented that illustrates a complex situation followed by questions that probe for the rationale and require additional reading. Frederickson uses concept mapping, requiring students to place nursing actions in sequence followed by a question about the effect that an additional nursing diagnosis might have on nursing interventions. Students then must discover from their written and practical resources, how this additional diagnosis will affect their decisions and provide rationales based on additional readings. This strategy has the potential to promote development of the seven cognitive skills and many of the 10 habits of mind.

\section{Example of Students' Outcomes}

In a nutrition course, in response to the prompter-predict how a New York City regulation that trans-fats must be labeled in restaurants will affect public health—a representative student response was:

The National Restaurant Association called the ban burdensome and unnecessary. They do not believe that a municipal health agency has any business banning a product the Federal Drug Administration has already approved. Fast-food restaurants and other major chains were particularly interested in the board's decision, because for these companies, a trans-fat ban would not just involve substituting one ingredient for another. In addition to overhauling recipes, the restaurants have to disrupt nationwide supply operations and try to convince customers that the new french fries and doughnuts will taste just as good as the originals. New York City's move to ban trans-fats has mostly been applauded by health and medical groups, although the American Heart Association warns that if restaurants are not given ample time to make the switch, they could end up reverting to ingredients high in saturated fat, like palm oil.

\section{H. Debates}

The eighth strategy is to promote student debates on controversial subjects. This provides students with opportunities to use all of the cognitive skills, with emphasis on analyzing, logical reasoning, and discriminating but also including predicting and transforming knowledge. A debate promotes confidence, a critical thinking habit of mind, and develops students' skills to articulate before an audience, albeit an audience that is not in view. The teacher provides a pool of acceptable topics within the discipline. Students then choose an issue from the entire pool, take a position on the topic they have chosen, and present their arguments defending that point of view. Students have opportunities to counter the arguments of two or three of their classmates. The author of the original position should also have 
opportunities to respond to critics, which forces the author to re-examine the completeness of approach to the topic in light of counter arguments or other points of view. An example of a debate in a nutrition class is when students take the positive and negative sides take sides in relation to the use of high fructose corn syrup in the food supply.

\section{Example of Students' Outcomes}

A lively debate in a nursing class occurred on the topic of promoting vasectomy in men versus the sterility methods typically used in women. Following library searches, both sides of the discussion were argued and followed by each side responding to questions posed by the other. The debate panel made up of classmates voted on categories such as ability to effectively articulate (write) thoughts, persuasiveness of arguments, citing of experts, timing, clarity of facts delivered, logic of argument, and knowledge learned by audience. This particular debate question has been used by the author with four different classes over five years. With each class, both sides of the debate have been able to present very persuasive arguments, twice ending in a tie vote, and the pro and con side winning once in other discussions of the issue. Students have admitted they approached the subject having a preconceived opinion but left not being swayed one way or the other; a few indicated a change of mind while others felt they needed to search additional resources on their own.

\section{Journals}

The ninth strategy, requiring course-related journal-writing, specifically promotes the habit of mind of reflection, but can also promote all of the cognitive skills and habits of mind. Journaling enables development of acceptable writing skills and helps students to clarify their thinking and explore their personal epistemology $[2,13]$. The focus of a journal can actually be the students' awareness of the thinking processes being used for discipline-related tasks, i.e., metacognition or thinking about thinking. A critical thinking theoretical framework such as in Table 1 is provided to students. Students use this framework to identify in a written journal the thinking processes that they used in course assignments, e.g., deciding what is the nursing diagnosis [14]. A journaling experience might benefit a nutrition assignment that requires students to become aware of their own values, prejudices, and beliefs, e.g., about obesity, overweight dietitians, new mothers who bottle feed, and parents who take their children to fast food restaurants.

Reflective journaling is also useful to develop the cognitive skill of transforming knowledge such as with a goal of fostering cultural competence and social responsibility. According to Rubin [15, p. 460], the virtues of compassion, righteousness, propriety, and wisdom can be measured by selecting key words and phrases found in individual student journals. The presence of these virtues may indicate enhanced cultural understanding.

\section{Example of Students' Outcomes}

In an online course on gender and stress, in which private journaling is a requirement, the outcomes of journaling are discussed in the last two online class sessions. Students' postings have supported the outcomes of improved attitudes, beliefs and behaviors related to culture and gender. In a course unit on stress and women with multiple roles, one student wrote:

I have a new respect for myself. My family has always been very traditional. My mother stayed home with us kids and waited on my father when he came home. I have felt inadequate as a wife and mother, feeling that I'm not as good as my mother. After our discussions on $\mathrm{Bb}$ and writing 
down my feelings in my journal, I see that I don't fit the mold of my mother. I have a job, take care of the kids and my husband and go to school. Sometimes I become crabby with my family and friends. I guess I'm just tired. I now see that I need to be kinder to myself, more forgiving. I do a lot and I'm NOT MY MOTHER.

There were more than 40 exchanges responding to this posting in a class of 16 , who were mostly female.

\section{J. Reinforce Students' Use of Critical Thinking}

Learning through critical thinking cannot take place without the use of reinforcement, the tenth strategy, which implies that there exists a connection between a stimulus (e.g. the question) and a response (student's exploration to find the answer). As observed by educational psychologist Thorndike, who is credited with developing the theories of stimulus-response and Law of Effect almost a century ago, "Of several responses made to the same situation, those which are accompanied or closely followed by satisfaction will, other things being equal, be more firmly connected with the situation so that when it recurs, they will be more likely to recur...The greater the satisfaction or discomfort, the greater the strengthening or weakening of the bond" [16]. Thorndike has authored hundreds of publications and has contributed to advancing the theories on learning and the learning process. Even today Thorndike's stimulus-response theory is highly valued and quoted among educators [17, p.170].

Teachers encourage and reinforce critical thinking when they establish a learning environment that is conducive to exploring the unknown, truth-seeking, open-mindedness, logical reasoning, flexibility, and so forth. This can be done through praise and positive reinforcement. When students participate in class discussions and the teacher responds with "good," or "that's an interesting point," or "keep up the good work," and so forth, students provide further input because they appreciate the positive reinforcement. Other ways that teachers reinforce students' critical thinking efforts are to respond to students' papers, tests and journals within a specific time period, e.g., a week or two. Students are encouraged when they know their postings are being read.

\section{Example of Students' Outcomes}

In an online course on gender and stress, the topic for discussion included areas such as: pregnancy and child rearing, multiple roles for women, adolescence, and body image. During the discussion of pregnancy, one of the men posted an inappropriate joke about women's roles and their genitals. The teacher deleted the post and began a lengthy discussion with him through email about the appropriateness of behavior and professional discussions about women and their roles. After a few exchanges, he was open to the idea that cultural background and socialization experiences influence one's beliefs and behaviors. After numerous interactions, he began posting on $\mathrm{Bb}$ with his classmates, shared a synopsis of the experience, and invited others to share their experiences about changing behaviors to fit a newly adopted culture, beliefs and behaviors. In the end of semester evaluations, students commented that this $\mathrm{Bb}$ discussion experience was one of the most important in changing their thinking and approaching nursing situations with more flexibility and openness.

\section{SUMMARY/CONCLUSIONS}

Critical thinking is an intellectual process that is necessary for making clinical judgments [1, 2]. Traditionally, in health professions education, critical thinking was taught in clinical settings. Online teaching and learning, however, provide new opportunities for stimulating critical thinking for clinical 
problem solving. Online learning permits students the opportunity to review and re-review lectures and discussions thus enabling additional thinking time. This enhances the ability to learn, reflect, and problem solve through the use of critical thinking strategies. Faculty members foster critical thinking through the skilled use of coaching, re-directing, focusing and skilled questioning techniques that assist to keep all participants fully engaged in the process. Online teaching methods enable a kind of "stick to it" format that is not possible in in-class teaching based on a number of factors such as insufficient time, verbose versus quiet students, intimidation, and environmental issues.

The authors described ten different strategies that can be employed to stimulate critical thinking in on-line teaching. These ten strategies, when used interchangeably, encourage depth and breadth of thinking and generate examination of clinical issues from more than one perspective. To maintain and stimulate student interest and involvement, each of the different approaches needs to be varied and challenging. Through online teaching, instructors can foster opportunities for students to actively engage in critical thinking processes.

\section{ACKNOWLEDGEMENTS}

Development of this paper was partially funded by a grant from the Alfred P. Sloan Foundation awarded to The City University of New York (CUNY) and the individual authors as CUNY faculty members who teach online courses. We also acknowledge the students in our online courses whose discussion board posts are quoted in this paper. Any names within the quotes were changed to maintain anonymity.

\section{REFERENCES}

1. Willingham, D. T. Critical thinking: Why is it so hard to teach? American Educator 31(2): 8-19, 2007.

2. Gambrill, E. Critical thinking in clinical practice: Improving the quality of judgment and decisions, $2^{\text {nd }}$ ed. Hoboken, NJ: John Wiley, 2005.

3. Paul, R., L. Elder, \& T. Bartell. A brief history of the idea of critical thinking. California Teacher Preparation for Instruction in Critical Thinking: Research Findings and Policy Recommendations: State of California. Sacramento, CA: California Commission on Teacher Credentialing, March 1997. Online: http://www.criticalthinking.org/aboutCT/briefHistoryCT.cfm.

4. Rubenfeld, M. G., \& B. K. Scheffer. Critical Thinking TACTICS for Nurses. Boston: Jones \& Bartlett, 2006.

5. Walker, G. Critical thinking in asynchronous discussions. International Journal of Instructional Technology and Distance Learning 2(6): 15-22, 2005. http://www.itdl.org/Journal/Jun 05 /article02.htm.

6. Brunt, B. A. Critical thinking in nursing: An integrated review. The Journal of Continuing Education in Nursing 36(2): 60-67, 2005.

7. Sternberg, R. J. Successful intelligence: How practical and creative intelligence determine success in life. New York: Penquin Books, 1997.

8. Browne, M. N., \& S. M. Keeley. Asking the right questions: A guide to critical thinking, $8^{\text {th }}$ ed. Upper Saddle River, NJ: Pearson Prentice Hall, 2007.

9. Moore, B. N. \& R. Parker. Critical thinking ( $8^{\text {th }}$ ed.). New York: McGraw Hill, 2007.

10. Paul, R. \& L. Elder. Critical thinking: Tools for taking charge of your learning and your life, $2^{\text {nd }}$ ed. Upper Saddle River: Pearson Prentice Hall, 2006.

11. Scheffer, B. K., \& M. G. Rubenfeld. A consensus statement on critical thinking. Journal of Nursing Education 39(8): 352-359, 2000. 
12. Harris, R. A. The plagiarism handbook: Strategies for preventing, detecting, and dealing with plagiarism. Los Angeles: Pyrczak Publishing, 2001.

13. Blake, T. K. Journaling: An active learning technique. International Journal of Nursing Education Scholarship 2(1): Article 7, April 2005. http://www.bepress.com/ijnes/vol2/iss1/art7.

14. Lunney, M. Critical thinking and nursing diagnosis: Case studies and analyses. Philadelphia: NANDA International, 2001.

15. Rubin, R. W. Developing cultural competence and social responsibility in preclinical dental students. Journal of Dental Education 68(4): 460-467, 2004. http://www.jdentaled.org/cgi/reprint/68/4/460.

16. Thorndike, E. L. Animal intelligence. New York: Macmillan, 1911. http://psychclassics.yorku.ca /Thorndike/Animal/chap5.htm.

17. Gibboney, R. A. Centennial reflections: Intelligence by design: Thorndike versus Dewey. Phi Delta Kappa 88(2):170-172, 2006.

\section{ABOUT THE AUTHORS}

Margaret Lunney, RN, PhD is a Professor at The College of Staten Island, The City University of New York.

Keville Frederickson, RN, EdD, FAAN is a Professor at Lehman College, Director of the DNS Program at the CUNY Graduate Center and a Faculty Fellow in the Office of the Dean of Nursing and Health Sciences, The City University of New York.

Arlene Spark, EdD, RD, FADA, FACN is an Associate Professor at Hunter College, The City University of New York.

Georgia McDuffie, RN, PhD is a Professor at Medgar Evers College, CUNY Brooklyn, NY. 